\title{
COMPORTAMENTO ALIMENTAR DO CAMARÃO DE ÁGUA DOCE, MACROBRACHIUM ROSENBERGII (DE MAN) (CRUSTACEA, PALAEMONIDAE) DURANTE A FASE LARVAL: ANÁLISE QUALITATIVA
}

\author{
Helenice P. Barros ${ }^{1}$ \\ Wagner C. Valenti ${ }^{2}$
}

\begin{abstract}
FEEDING BEHAVIOR OF THE PRAWN, MACROBRACHIUM ROSENBERGII (DE man) (Crustacea, Palaemonidae), during the larval phase: Qualitative ANALYSIS. Feeding behavior of the larvae's prawn, Macrobrachium rosenbergii De Man, 1879, in each stage of development was studied face at Artemia Linnaeus, 1758 nauplii, dry and wet diets. Groups of ten larvae in each stage were placed in $500 \mathrm{ml}$ beakers at $29^{\circ} \mathrm{C}$ in filtered brackish water. After the fasting period of acclimatization, the three types of food were offered separately to the larvae and the feeding behavior was observed during $30 \mathrm{~min}$. Feeding perception, capture, grasp and ingestion of food were used to determine feeding pattern. Stage I larvae do not eat. The feeding behavior of larvae was similar on the stages II - XI. The perception in distance does not occur in most individuals; the feeding process generally started with the physical contact of food with the animal. Food is captured by thoracic appendages (maxillipeds until stage III, and maxillipeds + pereopods in stages IV - XI) and particles are grasped and handled by maxillipeds. In opposition at the capture, the ingestion is a seletive process. Selective responses decrease in later stages and larvae become omnivorous in greater degree.
\end{abstract}

KEY WORS. Macrabrachium rosenbergii, larvae, feeding behavior

Macrobrachium rosenbergii (De Man, 1879) destaca-se como a espécie de camarão de água doce mais adequada para cultivo devido às suas características biológicas, tais como fácil reprodução em cativeiro, alta fecundidade, rápida taxa de crescimento, rusticidade e resistência a doenças (SICK \& BEATY 1974; COELHO et al. 1981; VALENTI 1985). Além disso, sua tecnologia de cultivo é bem conhecida.

A alimentação é um dos fatores mais importantes que afetam o desenvolvimento larval de crustáceos decápodes e o sucesso do cultivo comercial de larvas desses animais depende da utilização eficiente e econômica de alimentos disponíveis (Yufera et al. 1984; FreEMAN 1990). De um modo geral, em todo mundo, a alimentação das larvas de $M$. rosenbergii é baseada no fornecimento de náuplios

1) Curso de Pós-graduação em Aqüicultura, Centro de Aqüicultura, Universidade Estadual Paulista, Núcleo de Estudos em Biologia, Ecologia e Cultivo de Crustáceos. 14870-000 Jaboticabal, São Paulo, Brasil.

2) Faculdade de Ciências Agrárias e Veterinárias e Centro de Aqüicultura, Universidade Estadual Paulista, Núcleo de Estudos em Biologia, Ecologia e Cultivo de Crustáceos. 14870-000 Jaboticabal, São Paulo, Brasil. 
recém-eclodidos de Artemia associados à ração balanceada, musculatura de peixe ou rotíferos (MURAI \& ANDREWs 1978; NEW 1990). Até o presente, não foi possível a substituição completa de alimento vivo na larvicultura desta espécie. A baixa eficiência de dietas formuladas vem sendo atribuída ao limitado conhecimento das necessidades nutricionais das larvas e, conseqüentemente, ao fato destas dietas se apresentarem nutricionalmente inadequadas (NEW 1976; SORGELLOS \& LÉGER 1992). Porém, o sucesso de dietas para manutenção larval de peixes e crustáceos é dependente de outros fatores além da qualidade nutricional. A falta de informações sobre a forma como os animais percebem, capturam, ingerem e assimilam o alimento pode representar um ponto de estrangulamento na formulação de rações artificiais (MOOLER 1978). Além disso, devem ser considerados os critérios de seleção pelas larvas, como tamanho, forma e textura adequados das partículas, além da atratividade (MEYERS \& HAGOOD 1984; SORGELLOS \& LÉGER 1992).

Outro aspecto importante é que o desenvolvimento larval de decápodes é caracterizado por um número de estágios que necessitam de diferentes regimes alimentares durante o ciclo, de acordo com o comportamento, morfologia, necessidades nutricionais e energéticas dos indivíduos (SORGELLOS \& LÉGER 1992). Assim, é importante que esquemas de alimentação para o cultivo sejam específicos para cada estágio e baseados no comportamento de cada um (LOYA-JAVELLANA 1989).

Neste trabalho foi realizado um estudo qualitativo do comportamento alimentar das larvas de $M$. rosenbergii frente a alimentos comumente utilizados em aqüicultura, com objetivo de fornecer subsídios para o estabelecimento de um sistema de alimentação adequado para o bom desenvolvimento da espécie durante a fase larval. Larvas em cada estágio de desenvolvimento receberam alimento vivo, constituído por náuplios recém-eclodidos de Artemia, e alimento preparado, representado por rações seca e fresca, tendo sido investigado o comportamento dos camarões quanto ao modo de percepção, captura, apreensão e ingestão de cada ítem.

\section{MATERIAL E MÉTODOS}

Foram utilizadas larvas provenientes de várias fêmeas obtidas do estoque de reprodutores do Setor de Carcinicultura, Centro de Aqüicultura, Universidade Estadual Paulista (CAUNESP). Após a eclosão, os animais foram estocados, numa densidade de aproximadamente 90 larvas/l em um tanque cilíndrico, de fundo cônico, com capacidade para $120 \mathrm{l}$, provido de sistema fechado de circulação de água e aquecimento. A temperatura da água foi mantida ao redor de $29^{\circ} \mathrm{C}$ e a salinidade em 12\%o. A alimentação constou exclusivamente de náuplios recém-eclodidos de Artemia, fornecidos ad libitum duas vezes ao dia. Lotes de larvas nos diferentes estágios de desenvolvimento foram retirados desse plantel para a realização das observações. Os estágios foram identificados sob estereo-microscópio de acordo com UNO \& KNOW (1969).

Foram realizadas observações qualitativas do comportamento alimentar das larvas em cada estágio de desenvolvimento por ocasião do fornecimento de alimento vivo, constituído por náuplios de Artemia, e de alimento preparado, representado 
por ração seca e fresca. A formulação das rações é apresentada nas tabelas I e II. Cada ítem alimentar foi testado separadamente, utilizando-se um lote diferente de larvas.

Tabela I. Ingredientes utilizados na preparação de $150 \mathrm{~g}$ de ração seca.

\begin{tabular}{lcc}
\hline \multicolumn{1}{c}{ Ingredientes } & Quantidade $(\mathrm{g})$ & Porcentagem (\%) \\
\hline Molusco & 50,00 & 9,02 \\
Peixe & 50,00 & 9,02 \\
Leite em pó & 20,00 & 3,61 \\
Farinha de trigo & 10,00 & 1,80 \\
Óleo de fígado de bacalhau & 4,00 & 0,72 \\
Ovos de galinha & 212,36 & 38,34 \\
Premix vitamínico & 3,80 & 0,69 \\
Premix mineral & 3,80 & 0,69 \\
Água & 200,00 & 36,11 \\
\hline
\end{tabular}

Tabela II. Ingredientes utilizados na preparação de $500 \mathrm{~g}$ de ração fresca.

\begin{tabular}{lcc}
\hline \multicolumn{1}{c}{ Ingredientes } & Quantidade $(\mathrm{g})$ & Porcentagem (\%) \\
\hline Farelo de trigo & 4,36 & 2,88 \\
Farelo de milho & 8,73 & 5,82 \\
Farelo de soja & 54,76 & 36,15 \\
Farinha de peixe & 27,37 & 18,07 \\
Farinha de camarão & 54,76 & 36,15 \\
Premix & 1,50 & 0,99 \\
\hline
\end{tabular}

Em cada observação, dez larvas do mesmo estágio de desenvolvimento foram colocadas em béqueres contendo $500 \mathrm{ml}$ de água salobra proveniente do tanque de larvicultura estoque. Esta foi previamente filtrada em tela de nylon com malha $125 \mu \mathrm{m}$ para eliminar os resíduos e náuplios de Artemia. Após um período de duas horas em jejum as larvas foram alimentadas de acordo com as respectivas condições experimentais.

A percepção, captura e ingestão dos alimentos pelas larvas foram observados a olho nú por 30 minutos após a introdução do alimento. Cada teste foi repetido por três vezes em épocas distintas. A temperatura foi mantida ao redor de $29,0^{\circ} \mathrm{C}$.

Para melhor descrição do padrão de tomada de alimento pelas larvas, foram também realizadas observações sob estereomicroscópio. Os animais de cada estágio foram colocados, individualmente, em placas de Petri, com duas a três gotas de água e foi fornecido o alimento. A observação foi encerrada quando ocorria ingestão e/ou rejeição do alimento oferecido. Cada ítem alimentar foi fornecido separadamente, utilizando-se larvas diferentes.

\section{RESULTADOS}

De modo geral, as larvas capturavam o alimento apenas quando este encostava em seus apêndices torácicos (maxilípedes e pereiópodos). Entretanto, verificou-se alguns casos de direcionamento e locomoção dos animais em busca de 
partículas de ração e náuplios de Artemia. Esse fato ocorreu sempre quando o alimento estava próximo e não se observou diferença na percepção dos três tipos de alimento testados. Não foi possível definir como as larvas detectavam a presença do alimento.

O modo de captura, apreensão, ingestão e/ou rejeição, tanto de partículas de ração seca como de ração fresca, foi basicamente o mesmo em todos os estágios de desenvolvimento.

Assim que as rações eram oferecidas, as larvas geralmente movimentavam rapidamente os exopoditos dos maxilípedes e, a partir do estágio II, também os pereiópodos, criando um fluxo que afastava as partículas de sua boca. Além disso flexionavam o último e maior par de pereiópodos contra o cefalotórax, dificultando, assim a entrada de partículas na região bucal. Quando uma partícula ficava presa entre seus pereiópodos, a larva flexionava fortemente o abdômen e, com um impulso para trás, escapava da mesma. Para que a captura e apreensão da partícula ocorresse, a larva invertia a orientação e diminuia o ritmo de movimentação dos exopoditos, criando um fluxo de água mais lento, e abria a cavidade ventral do cefalotórax estendendo os últimos pares de pereiópodos. Indivíduos de cada um dos onze estágios larvais capturaram partículas dos dois tipos de ração.

No estágio I de desenvolvimento, quando os pereiópodos ainda não estão presentes, as larvas agarravam as particulas de ração que tocavam em seus maxilípedes, fechando o exopodito do terceiro par junto ao corpo; dessa forma, seguravam o alimento entre os maxilípedes, sem manuseá-lo. Não ocorreu a ingestão neste estágio, mas observou-se constante movimentação das maxilas e mandíbulas quando as larvas agarravam as partículas.

A partir do estágio II, o último par de pereiópodos foi utilizado para capturar a partícula e levá-la até os maxilípedes, onde esta é apreendida e manuseada, sendo levada à boca; após manipulação do alimento na região oral, este foi ingerido ou rejeitado.

A ingestão se realizou aos poucos, e o alimento era cortado em pedaços menores e mastigado. Algumas larvas nos estágios I ao V capturavam partículas de ração e ficavam abraçadas a elas, sem manuseá-las ou ingerí-las, como se estas estivessem servindo de substrato.

Nos estágios iniciais houve grande rejeição tanto da ração fresca como da ração seca, sendo que a primeira foi ingerida apenas a partir do estágio VII, e a segunda a partir do estágio IX. A rejeição podia ocorrer mesmo sem que o animal encostasse o alimento na boca. As larvas largavam partículas e as afastavam após manuseá-las com os maxilípedes.

Foram verificados casos de egestão do alimento após a ingestão de ração seca. Algumas larvas, após capturarem, manusearem e começarem a ingerir partículas da ração, as rejeitaram, regurgitando-as.

O comportamento larval foi diferente quando foram fornecidos náuplios de Artemia. As larvas mexiam ativamente os exopoditos apenas nos momentos seguintes à introdução das presas. Observou-se movimentos repentinos de flexão abdominal, provocando um rápido deslocamento da larva, tanto vertical como horizontal- 
mente, com maior freqüência após o fornecimento de alimento. Após alguns minutos, diminuiam o ritmo de batimento dos apêndices e permaneciam praticamente paradas, com os pereiópodos estendidos, deixando, portanto, a cavidade cefalotorácica livre. Quando um náuplio esbarrava em seus pereiópodos, esta o abraçava com o maior par e o prendia com os maxilípedes, levando-o à boca e o ingerindo.

Náuplios de Artemia foram capturados e ingeridos com elevada freqüência por larvas nos estágios II ao XI. Nenhuma larva no estágio I capturou náuplios. Nos estágios II e III as larvas capturavam os náuplios e os manipulavam até posicioná-los de modo a começar a ingestão pela região abdominal; a região cefálica não era ingerida. O tempo de ingestão diminui gradativamente com o desenvolvimento dos animais, passando a aproximadamente 10 minutos no estágio II até um segundo nos estágios X e XI, quando as larvas engoliam o náuplio inteiro.

\section{DISCUSSÃO}

O comportamento alimentar das larvas de $M$. rosenbergii mostrou o mesmo padrão geral a partir do estágio II de desenvolvimento, caracterizado por captura, apreensão, manipulação, ingestão ou rejeição, indicando que este processo não sofre variações ontogenéticas nesta fase. Esse padrão é representado na figura 1.

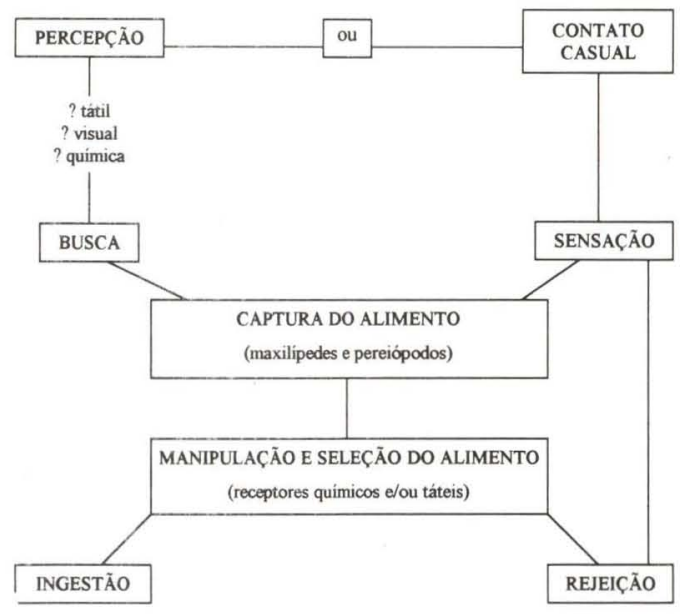

Fig. 1. Esquema do padrão de alimentação das larvas de M. rosenbergii.

Observou-se um aumento de aceitação dos dois tipos de alimento inerte com o desenvolvimento larval. A seletividade diminui durante o desenvolvimento e os animais vão tornando-se omnívoros em maior grau, aumentando sua capacidade de explorar os recursos alimentares disponíveis no ambiente.

De acordo com LINDSTEDT (1971), até mesmo a alimentação de organismos mais simples é acompanhada por uma série de padrões de comportamento. Embora esses padrões estejam relacionados entre si, podem ser considerados, também, como 
fenômenos separados, controlados por uma série de condições físicas e químicas particulares. Esse autor afirma que todos os passos do processo de alimentação são mediados por estímulos químicos que podem ativar ou interromper a alimentação. No entanto, as observações realizadas no presente estudo não indicaram a percepção dos alimentos e orientação em sua direção como regra em larvas de $M$. rosenbergii, pois a grande maioria delas só capturou partículas que tocaram em seu corpo.

Segundo ACHE (1982), quimiorecepção e mecanorecepção são reconhecidos como os principais sentidos usados pelos crustáceos decápodes para identificação de partículas alimentares. Este autor distingue duas séries de quimioreceptores: os antenulares, considerados como órgãos de olfato, e os dos dáctilos e peças bucais, os quais são órgãos de tato. Os quimioreceptores antenulares mediam a detecção de estímulos de baixo peso molecular a alguma distância do recurso de odor, despertando e/ou provocando comportamento de apetite e orientando o animal em direção ao alimento. Os quimioreceptores dos dáctilos e peças bucais, em contraste, mediam a detecção de estímulos próximos ou em contato com o recurso, controlando a captura e desencadeando o processo de ingestão e/ou rejeição do ítem alimentar.

Com base nessas informações, pode-se atribuir a dificuldade de percepção química à distância em larvas de $M$. rosenbergii ao fato das estruturas antenulares se desenvolverem ao longo do ciclo larval. MOLLER (1978) verificou sob microcópio que larvas de $M$. rosenbergii apresentaram agitação dos apêndices relacionados à alimentação e flexões antenais após a introdução de um estimulante de odor (solução de hemoglobina 1\%), mas não se deslocaram em sua direção; estas só emitiam comportamento de captura após o contato físico. No entanto, após a metamorfose, quando as antenas já estão formadas, o processo de orientação ocorreu e as pós-larvas nadaram ativamente em direção ao estímulo.

Em muitos crustáceos, a predação parece ser decorrente de oportunidade, ou seja, a presa é apreendida após contato físico ou muita proximidade com o predador (AMBlER \& Frost 1974; Grahame 1983). Dados obtidos com larvas de Palaemonetes Heller, 1869, M. rosenbergii, Pandalus borealis Kröyer, 1838, Homarus americanus Milne-Edwards, 1837, Penaeus monodon Fabricius, 1798 e Homarus gammarus (Linnaeus, 1758) têm demonstrado que estágios larvais planctônicos de decápodes não dispõem de comportamento de orientação em direção ao recurso alimentar, mas dependem da oportunidade de encontro para capturar o alimento (BRoAd 1957; Moller 1978; Meyers \& Hagood 1984; Stickney \& PERKInS 1981; HINTON \& COREY 1979; KURMAly et al. 1989, 1990). Embora a maioria dos resultados aqui obtidos corroborem essa afirmação, foi observado que uma parcela dos indivíduos detectaram e perseguiram tanto náuplios de Artemia como partículas de ração quando estas estavam caindo. Isto indica a existência de variação individual na acuidade dos sentidos de $M$. rosenbergii, que pode ser produzida pelo meio ambiente ou esta pode ser uma característica polimórfica, condicionada por diferentes genes alelos. Assim, pequena parte dos indivíduos da população teriam maior capacidade de explorar os recursos disponíveis e poderiam completar a metamorfose mais rapidamente. De fato, observa-se uma grande variação no tempo de desenvolvimento larval de animais resultantes de uma mesma eclosão (LING 1969; NEW \& SHINGOLKA 1985).

Revta bras. Zool. 14 (4): 785 - 793, 1997 
O fato de ter ocorrido ingestão de todas as dietas oferecidas por larvas de $M$. rosenbergii em todos os estágios de desenvolvimento, com exceção apenas do estágio I, quando estas se nutrem a partir do saco vitelínico, sugere que estas são vorazes e pouco seletivas, mastigando a maioria dos ítens que entram em contato com seus apêndices. A exploração do ambiente pela larva, portanto, parece baseada em tentativa e erro.

MOLLER (1978) e MEYERS \& HAGOOD (1984) verificaram que larvas de $M$. rosenbergii no estágio I não se alimentam e mostram total indiferença a alimentos oferecidos, mesmo quando em contato com seus apêndices torácicos, sugerindo ausência de qualquer tipo de percepção. No presente trabalho foi constatado que larvas neste estágio não ingeriram alimento, mas nossos dados indicaram que a percepção tátil existe, uma vez que foram observadas várias larvas agarrarem as partículas após o contato físico com elas. Além disso, ao tocar a ponta de um estilete em seus maxilípedes, as larvas o agarraram firmemente. Esta pode ser outra característica polimórfica da espécie.

Foi observado que $M$. rosenbergii utiliza os maxilípedes e pereiópodos tanto para a locomoção como para a captura do alimento. Esse fato, também foi observado por MOOLER (1978) em animais dessa mesma espécie e em Macrobrachium idella (Hilgendorf, 1898) por PILlaI \& MoHAmEd (1973), em Macrobrachium novaehollandiae (De Man, 1908) por THORNE et al. (1979), em Macrobrachium faustinum De Saussure, 1857 por HUNTE (1980), em Pandalus borealis por STICKNEY \& PERKINS (1981) e WIENBERG (1982) e em Homarus americanus por CAPUZZO \& LANCASTER (1979). Este parece ser padrão comum às larvas planctônicas de crustáceos.

Parece existir uma associação do movimento causado pela flexão abdominal com a captura do alimento em larvas de $M$. rosenbergii, pois náuplios eram ingeridos logo após este movimento. Pillai \& Mohamed (1973) e Wienberg (1982) acreditavam que essa relação exista em larvas de $P$. borealis e $M$. novaehollandiae, respectivamente, indicando que estímulos mecânicos parecem ser primariamente responsáveis pela atividade do comportamento predatório.

$\mathrm{O}$ fato de larvas nos estágios I ao $\mathrm{V}$ permanecerem agarradas a partículas de alimento sem se alimentar pode ser uma estratégia adotada pela espécie para aumentar o seu peso e controlar sua posição na coluna d'água com gasto mínimo de energia. Manter-se afastado da superfície pode ser vantajoso no ambiente natural, onde as larvas estão constantemente submetidas à correntes que podem carregá-las para área acima da tensão superficial ou para as margens, levando-as à morte.

Ao contrário da captura, que geralmente depende da oportunidade de encontro da larva com o alimento, a ingestão é um processo seletivo que tem origem nos maxilípedes, pois observou-se rejeição após a manipulação das partículas. Em contato com os maxilípedes e peças bucais, tanto estímulos mecânicos como químicos podem ter papel importante para a ingestão. A importância da palatabilidade no processo de ingestão em larvas de decápodes foram obtidas por MOLLER (1978), Meyers \& HAGGOD (1984) e Kurmaly et al. (1989, 1990). Por outro lado, deve-se considerar que a seletividade depende de outros fatores, tais como a disponibilidade e qualidade nutricional do alimento (DEMOTT 1988). 
AGRADECIMENTOS. Agradecemos ao Prof. Dr. Gilson Luiz Volpato e ao Prof. Dr. Matheus José R. Paranhos da Costa pelas preciosas sugestões e ao CNPq pela bolsa concedida.

\section{REFERÊNCIAS BIBLIOGRÁFICAS}

ACHE, B. 1982. Chemoreception and thermoreception, p. 369-398. In: H.L. ATwOOD. \& D.C. SANDERMAN (Ed.). The Biology of Crustacea. New York, Academic Press, vol. 3, 479p.

AMBLER, J.W. \& B.W. FROST. 1974. The feeding behaviour of a predatory planktonic copepod, Tortanus discaudatus. Limnol. Oceanogr. 19: 446-451.

BROAD, A.C. 1957. The relationship between diet and larval development of Palaemonetes. Biol. Bull. 112 (2): 162-170.

CAPPUZzo, J.M. \& B.A. LANCASTER. 1979. Some physiological and biochemical considerations of larval development in the American lobster, Homarus americanus Milne Edwards. Jour. Exp. Mar. Biol. Ecol. 40 (1): 53-62.

Coelho, P.A.; M. Ramos-PorTo \& C.M.A. SoARES. 1981. Cultivo de camarões do gênero Macrobrachium Bate (Decapoda, Palaemonidae) no Brasil. Natal, EMPARN, vol. 6, 66p.

DEMOTT, W.R. 1988. Discrimination between algae and artificial particles by freshwater and marine copepods. Limnol. Oceanogr. 33 (3): 397-408.

Freeman, J.A. 1990. Regulation of tissue growth in crustacean larvae by feeding regime. Bio. Bull. Mar. Biol. Lab. Woods Hole 178 (3): 217-221.

GraHAME, J. 1983. Adaptative aspects of feeding mechanisms, p.65-107. In: Vernierg, F.J. \& W.B. Vernberg (Eds). The Biology of Crustacea. New York, Academic Press, vol. 8, 383p.

Hinton, D.J. \& S. COREY. 1979. The mouthparts and digestive tract in the larval stages of Homarus americanus. Can. Jour. Zool. 57 (7): 1413-1423.

HuNTE, W. 1980. The laboratory rearing of larvae of the shrimp Macrobrachium faustinum (Decapoda, Palaemonidae). Carib. Jour. Sci. 16 (1-4):57-62.

Kurmaly, K.; A.B. Yule, A.B. \& D.A. JonES. 1989. An energy budget for the larvae of Penaeus monodon (Fabricius). Aquaculture 81 (1): 13-25.

Kurmaly, K.; D.A. Jones \& A.B. YULE. 1990. Acceptability and digestion of diets fed to larval stages of Homarus gammarus and the role of dietary conditioning behaviour. Mar. Biol. 106 (2): 181-190.

LindSTEDT, K.J. 1971. Chemical control of feeding behaviour. Comp. Biochm. Physiol. 39A:553-581.

LING, S.W. 1969. The general biology and development of Macrobrachium rosenbergii (De Man). FAO Fis. Rep. 57 (3):589-606.

LOYA-JAVELLANA, G.N. 1989. Ingestion saturation and growth responses of Penaeus monodon larvae to food density. Aquaculture 81 (3-4):329-336.

MEYERS, S.P. \& R.W. HAGOOD. 1984. Flake diets and larval crustacean culture. Prog. Fish. Cult. 46 (4):225-229.

MOOLER, T.H. 1978. Feeding behaviour of larvae and postlarvae of Macrobrachium rosenbergii (De Man)(Crustacea, Palaemonidae). Jour. Exp. Mar. Biol. Ecol. 
35: 251-258.

Murai, T. \& J.W. ANDREWS. 1978. Comparison of feeds for larval stages of the giant prawn (Macrobrachium rosenbergii). Jour. World Maricult. Soc. 9: 189-193.

NEW, M.B. 1976. A review of dietary studies with shrimp and prawns. Aquaculture 9:101-144.

1990. Freshwater prawn culture: a review. Aquaculture 88: 99-143.

NEw, M.B. \& S. SHINGOLKA. 1985. Freshwater prawn farming. A manual for the culture of Macrobrachium rosenbergii. Roma, FAO Fish. Tech. Pap. 225, $116 \mathrm{p}$.

Pillai, N.N. \& K.H. Mohamed. 1973. Larval history of Macrobrachium idella (Hilgendorf) reared in the laboratory. Jour. Mar. Biol. Assoc. India 15 (1): 359-385.

SiCK, L.V. \& H. BEATY. 1974. Culture techniques and nutrition studies for larval stages of the giant prawn, Macrobrachium rosenbergii. Techn. Rep. Ser. 74 (5):32p.

SORGELlOS, P. \& P. LÉGER. 1992. Improved larviculture outputs of marine fish, shrimp and prawn. Jour. World. Aquacult. Soc. 23 (4): 251-264.

STICKNEY, A.P. \& H.C. PERKINS. 1981. Observations on the food of the larvae of the northern shrimp, Pandalus borealis Kröyer (Decapoda, Caridea). Crustaceana 40 (1): 36-49.

Thorne, M.J.; D.R. Fielder \& J.G. GreEnwood. 1979. Larval behavior of Macrobrachium novaehollandiae (De Man) (Decapoda, Palaemonidae). Aust. Jour. Mar. Freshwater Res. 30 (1): 11-23.

Uno, Y. \& KNow CHIN Soo. 1969. Larval development of Macrobrachium rosenbergii reared in the laboratory. Jour. Tokyo Univ. Fish. 55: 179-190.

VALENTI, W.C. 1985. Cultivo de camarões de água doce. Nobel, São Paulo, Brasil, 86 p.

WIENBERG, R. 1982. Studies on the influence of temperature, salinity, ligth, and feeding rate on laboratory reared larvae of deep sea shrimp, Pandalus borealis Krøyer 1838. Meeresforschung 29: 136-153.

Yufera, M.; A. Rodriguez \& L.M Lubian. 1984. Zooplankton ingestion and feeding behavior of Penaeus kerathurus larvae reared in the laboratory. Aquaculture 42: 217-224.

Recebido em 17.X.1996; aceito em 18.IX.1997. 